\title{
ENSINO MÉDIO INTEGRADO E PRÁTICAS PEDAGÓGICAS INTEGRADORAS: CAMINHOS PARA A FORMAÇÃO HUMANA INTEGRAL
}

\author{
L. M. SILVA*, T. G. S. MELO e J. P. NASCIMENTO \\ Instituto Federal de Educação, Ciência e Tecnologia do Rio Grande do Norte \\ luzmoreira2009@gmail.com*
}

Artigo submetido em outubro/2015 e aceito em dezembro/2015

DOI: $10.15628 /$ rbept.2015.3560

\section{RESUMO}

O Ensino Médio Integrado é uma etapa da Educação Básica que a partir do Decreto no 5.154/2004 retorna à realidade legal brasileira na intenção de integrar a formação humana com a formação profissional garantindo uma formação integral para os sujeitos. Assim, o presente artigo tem como temáticas centrais o Ensino Médio Integrado e as Práticas Pedagógicas Integradoras desenvolvidas a partir da implementação do referido decreto até o ano de 2014. Essa pesquisa possui como objetivo analisar as propostas de práticas pedagógicas integradoras que possibilitam a materialização do Ensino Médio Integrado na conclusão da Educação Básica. Para tanto, desenvolvemos uma pesquisa bibliográfica e utilizamos como referencial teórico o materialismo histórico dialético fazendo uma análise detalhada e crítica sobre o contexto estudado interpretando a realidade e apontando possibilidades de uma formação humana integral. A partir desse estudo foi possível constatar que o Ensino Médio integrado é um desafio e que as práticas pedagógicas podem ou não ser integradoras, dependendo dos objetivos e finalidades com que são desenvolvidas, ou seja, dependendo da visão e do projeto de sociedade em que se acredita e defende.

PALAVRAS-CHAVE: Práticas Pedagógicas, Ensino Médio Integrado, Formação Humana Integral

\section{INTEGRATED HIGH SCHOOL EDUCATION AND PEDAGOGICAL PRACTICES: APPROACHES TO AN INTEGRAL HUMAN FORMATION}

\begin{abstract}
The Integrated School Education is a basic step that from the Decree No. 5.154 / 2004 returns to the Brazilian legal reality in an attempt to integrate human development with professional training ensuring a comprehensive training for the subjects. Therefore, this article central themes are Integrated School and Integrators Pedagogical Practices developed after the decree by the year of 2014. This research aims to analyze the proposals of integrative teaching practices that enable the
\end{abstract}

achievement of Integrated Education on finishing basic education. It was carried out a literature research and a theoretical dialectical historical materialism was used in order to make a detailed and critical analysis of the context studied interpreting reality and pointing out possibilities of an integral human formation. From this study it was found that the integrated high school is a challenge and that the pedagogical view and social project that is believed and standed for.

KEYWORDS: Pedagogical Practices. Integrated high school. Integral Human Formation. 


\section{INTRODUÇÃO}

Este estudo constitui uma tentativa de explicar o que é o Ensino Médio Integrado e como ele se materializa como última etapa da Educação Básica brasileira na intenção de promover uma formação humana e integral aos sujeitos que se encontram nessa etapa. Para tanto, procuramos conceituar as práticas pedagógicas integradoras como sendo possibilidades de efetivar a integração do Ensino Médio com o Ensino Técnico, diante das dificuldades encontradas na realidade brasileira.

Dessa forma, o texto está constituído de duas partes seguidas das considerações finais. $\mathrm{Na}$ primeira parte, procurou-se contextualizar o Ensino Médio na realidade brasileira evidenciando a questão das matrículas nessa etapa da Educação Básica nos últimos anos e a relevância dessa etapa considerando a relação existente entre as categorias educação e trabalho e a necessidade de pensar em práticas que promovam a integração entre o Ensino Médio e o Ensino Técnico a fim de alcançar as finalidades propostas para essa etapa.

Na segunda parte do texto procurou-se esclarecer a relação entre teoria e prática, assim como enfatizar a relevância das práticas pedagógicas integradoras, considerando os saberes dos estudantes e princípios como a contextualização e a interdisciplinaridade na definição de um currículo integrado e dessas práticas que possibilitam a formação humana integral.

A discussão é finalizada com considerações sobre a necessidade de soluções mais amplas e profundas, que nasçam nas concepções éticas e políticas sobre a realidade para então se definir práticas pedagógicas emancipadoras, capazes de promover a formação de cidadãos críticos e conscientes da necessidade de transformação social.

\section{ENSINO MÉDIO INTEGRADO E A POSSIBILIDADE DE FORMAÇÃO HUMANA INTEGRAL}

O Ensino Médio constitui uma etapa da educação brasileira que vem sendo negligenciada. Um dado que evidencia essa negligência compreende a redução de matrículas no Ensino Médio brasileiro. Segundo dados do Instituto Nacional de Estudos e Pesquisas Educacionais Anísio Teixeira (INEP) no ano de 2006 o número de matrículas chegou a 8.906.820, já em 2013 consta 8.312.815 o número de matrículas. Em cinco anos esse número reduziu em 594.005. Quanto a isso Grabowski (2005, p. 6) afirma que "Apenas 45\% dos jovens no Brasil concluem o Ensino Médio e, a maioria destes, em torno de $60 \%$, o fazem em condições precárias: noturno e/ou supletivos". Não apenas observando esses dados, mas os levando em consideração, o Ensino Médio no Brasil caracteriza-se como uma etapa que merece preocupação, principalmente dos educadores.

De acordo com a Lei de Diretrizes e Bases da Educação Nacional (BRASIL, 1996, p. 28-29), o Ensino Médio compreende a etapa final da Educação Básica, tendo as seguintes finalidades:

I - a consolidação e o aprofundamento dos conhecimentos adquiridos no ensino fundamental, possibilitando o prosseguimento de estudos;

II - a preparação básica para o trabalho e a cidadania do educando, para continuar aprendendo, de modo a ser capaz de se adaptar com flexibilidade

a novas condições de ocupação ou aperfeiçoamento posteriores; 
III - o aprimoramento do educando como pessoa humana, incluindo a formação ética e o desenvolvimento da autonomia intelectual e do pensamento crítico;

IV - a compreensão dos fundamentos científico-tecnológicos dos processos produtivos, relacionando a teoria com a prática, no ensino de cada disciplina.

Observamos que nessa etapa da educação, há como pressuposto uma maior articulação entre a educação e o trabalho. Para trilhar esta pesquisa buscamos fundamentar a categoria trabalho em Marx. Segundo este autor, o trabalho "[...] é um processo entre o homem e a Natureza, um processo em que o homem, por sua própria ação, media, regula e controla seu metabolismo com a Natureza." (1996, p. 297). Assim, o ser humano "[...] realiza, ao mesmo tempo, na matéria natural seu objetivo, que ele sabe que determina, como lei, a espécie e o modo de sua atividade e ao qual tem de subordinar sua vontade." (MARX, 1996, p. 298). Esse aspecto ressalta o caráter teleológico do trabalho, ou seja, a capacidade de projetar, eminentemente do ser humano.

O trabalho é um elemento situado histórica, social e economicamente. E por isso não pode ser compreendido sem o levantamento dessas características. Sobre isso, é interessante um pensamento de Marx, ao afirmar que

Tão pouco quanto o sabor do trigo revela quem o plantou, podem-se reconhecer nesse processo as condições em que ele decorre, se sob o brutal açoite do feitor de escravos ou sob o olhar ansioso do capitalista, se Cincinnatus o realiza ao cultivar suas poucas jugera ou o selvagem ao abater uma fera com uma pedra. (MARX, 1996, p. 303).

Ao produzir um produto, o mesmo não nos diz de forma imediata sob que processo e condições de trabalho foram necessários para sua realização. A produção capitalista corrobora para a fragmentação da compreensão do processo de trabalho. Assim, neste estudo, ao ter como objeto o Ensino Médio Integrado, é fundamental compreender o trabalho no sistema capitalista. Logo, não constitui lugar comum, reforçar que esse sistema é caracterizado pela divisão entre burguesia e proletariado. Marx e Engels (1998) na obra "Manifesto Comunista", definem por burguesia (capitalistas), como classe detentora dos meios de produção social, e por proletariado (trabalhadores) como a classe dos assalariados, que são obrigados a vender sua força de trabalho como meio para sobreviver. Assim, sob o processo capitalista de produção

O trabalhador trabalha sob o controle do capitalista a quem pertence seu trabalho. 0 capitalista cuida de que o trabalho se realize em ordem e os meios de produção sejam empregados conforme seus fins, portanto, que não seja desperdiçada matéria-prima e que o instrumento de trabalho seja preservado, isto é, só seja destruído na medida em que seu uso no trabalho o exija. (MARX, 1996, p. 304).

Dessa forma, fica claro que o processo de trabalho no capitalismo ocorre, a partir da exploração do capitalista sob o dispêndio do trabalho do proletariado. Não obstante, as formas de exploração dentro do capitalismo possuem especificidades conforme a maneira como está organizada a produção. Além disso, de acordo com Kuenzer (2007), sob as bases do regime de acumulação do taylorismo-fordismo há uma intensificação da separação entre teoria e prática, e da oferta de educação destinada às classes dirigentes e aos trabalhadores. 
Em busca da então articulação educação e trabalho, o Ensino Médio Integrado possui como proposta a integração do Ensino Médio e do Ensino Técnico de nível médio, assumida por meio do decreto $\mathrm{n}$ o 5.154/04 (GRABOWSKI, 2005). Assim essa etapa

[...] possui um significado e um desafio para além da prática disciplinar, interdisciplinar ou transdisciplinar, pois implica um compromisso de construir uma articulação e uma integração orgânica entre o trabalho como princípio educativo, a ciência como criação e recriação pela humanidade de sua natureza e cultura, como síntese de toda produção e relação dos seres humanos com seu meio. Portanto, ensino integrado implica um conjunto de categorias e práticas educativas no espaço escolar que desenvolvam uma formação integral do sujeito trabalhador. (GRABOWSKI, 2005, p. 9).

Dessa forma, justifica-se a relevância dessa etapa de ensino em nossa sociedade e na busca dessas práticas educativas preocupadas e orientadas para uma formação humana integral.

Ao vivermos em um sistema econômico, político e social que perpetua a fragmentação em todas as esferas, existe uma necessidade social de se compreender a realidade, de se buscar a recomposição da totalidade, visto que "Se a realidade existente é uma totalidade integrada não pode deixar de sê-lo o sistema de conhecimentos produzidos pelo homem a partir dela, para nela atuar e transformá-la." (MACHADO, 2010, p. 50). Por essa razão, segundo Kuenzer (2010, p. 868), faz-se necessário

[...] construir uma proposta de Ensino Médio integrado que supere a mera justaposição dos componentes geral e específico dos currículos, sem cair no engodo de projetos com reduzida sistematização do conhecimento e a negar a necessidade de formação teórica para os trabalhadores, mediante uma rigorosa articulação entre teoria e prática, a partir da prática social e dos processos de trabalho.

Mais uma vez, enfatiza-se a necessidade de articulação entre teoria e prática, educação e trabalho. Vale salientar, que o Ensino Médio Integrado não é a única proposta de ensino cujo objetivo seja uma recomposição da totalidade, tampouco devemos considerá-lo como um caminho salvacionista, ao qual se tem evocado à educação, mas sim ter claro que esse se constitui em um dos caminhos, sem esquecer que a realidade concreta é muito mais rica. A possibilidade dessa integração, também passa pela defesa de um currículo integrado. Esse currículo deve estar efetivamente vinculado

[...] à vida dos educandos, à dinâmica da interação e dos processos históricos, sociais, econômicos e culturais relevantes que estes vivenciam. Elementos significativos do passado, que precisam se integrar aos fatos cruciais do presente. Elementos do conhecimento empírico e da cultura que trazem os educandos a partir de suas experiências de vida, que precisam juntar-se aos conhecimentos científicos para significá-los. (MACHADO, 2005 p. 53).

Lembrando que esse currículo não deve partir de uma justaposição de conteúdos. Essa confusão gera a superposição de disciplinas, que sequer dialogam os conteúdos. Isto ocorre devido a uma hierarquização dos conhecimentos que faz com que uns tenham mais importância que outros e sejam trabalhados de forma fragmentada. Para a superação desse problema é preciso 
uma mudança na postura pedagógica de forma que o currículo seja pensado a partir da articulação dos conhecimentos de modo a possibilitar aprendizagens significativas.

É preciso ter clareza que a busca do Ensino Médio Integrado não deve ser a atividade fim. Nos marcos de uma sociabilidade capitalista, não é possível uma escola que consiga contemplar e ceifar a dualidade da oferta de ensino. Por outro lado "A superação desse tipo de sociedade é que viabiliza as condições para que todos possam dedicar-se, ao mesmo tempo, ao trabalho intelectual e ao trabalho manual." (SAVIANI, 2003, p. 139). Por isso é preciso conceber que "[...] a politecnia supõe a articulação entre o trabalho manual e o intelectual." (SAVIANI, 2003, p. 141). Ainda de acordo com Saviani, a defesa da politecnia pressupõe o domínio dos fundamentos científicos, assim como a técnicas que utilizadas no processo de trabalho.

Por tudo isso, o Ensino Médio Integrado, pode ser considerado como um ponto de resistência, como uma forma de ensino que caminhe no sentido de cada vez mais recompor a compreensão de totalidade da realidade. Logo, fundamentado nas ideias defendidas por autores como Frigotto (2011), Ciavatta (2011), Kuenzer (2010), Moura (2011) e Ramos (2005), essa modalidade pode representar uma espécie de travessia para a politecnia. Assim, no próximo item dessa pesquisa, serão apontadas e discutidas práticas pedagógicas que possibilitem o Ensino Médio Integrado.

\section{O PAPEL DAS PRÁTICAS PEDÁGOGICAS NO ENSINO MÉDIO INTEGRADO: UMA REFLEXÃO NECESSÁRIA PARA A GARANTIA DE UMA EDUCAÇÃO EMANCIPATÓRIA}

Tomando como desafio a efetivação do Ensino Médio integrado, faremos reflexões sobre a importância das práticas pedagógicas como possibilidades de promover uma educação emancipadora para os adolescentes, jovens e adultos que estão concluindo a última etapa da Educação Básica. Portanto, essa parte do texto é dedicada ao conjunto de princípios, concepções, procedimentos e técnicas que podem constituir veículos de integração no Ensino Médio Integrado - EMI. Para isso é necessário considerar como se materializam a teoria e a prática nesse processo educativo e comecemos por compreender esses dois conceitos.

Sobre teoria e prática Vasquez (1977) as definem como dois componentes indissolúveis da "práxis". Assim, devemos reconhecer que no processo educativo, ambas devem estar intensamente imbrincadas de forma que uma alimente a outra mutuamente conforme expressa a afirmação a seguir

[...] é indispensável que a teoria tenha já nascido de uma prática real naqueles a quem se dirige, que seja a tomada de consciência da prática ou, pelo menos, dos sentimentos que os animam e que eles gostariam de ver encarnados na prática. (SNYDERS 1974, p.206, apud CANDAU, 1994, p. 55).

Nessa perspectiva os educadores são convidados a pensar e articular suas práticas considerando essa característica de indissolubilidade entre teoria e prática e procurando definir ações centradas na objetividade da realidade e capazes de promover transformações nessa realidade. 
Outro aspecto a ser considerado na definição de práticas integradoras é o trabalho coletivo, uma vez que a construção de um projeto de sociedade emancipada é responsabilidade de todos. Assim, o trabalho coletivo é essencial na construção do perfil de aluno que se almeja como fruto de um projeto de Ensino Médio Integrado. Segundo Hengenmühle (2004, p. 43):

O perfil do aluno que a escola se propõe há de ser fruto da construção e responsabilidade de todos. Sua definição pode ser desenvolvida a partir da equipe diretiva, a qual propõe, para a comunidade escolar interna (aluno, funcionários e professores) e externa (família, associação de bairro...), um referencial para o perfil que se pretende adotar.

Dessa forma, salientamos a importância do trabalho cooperativo, da capacidade de se trabalhar em equipe almejando a construção de processos educativos significativos, ou seja, que estejam de acordo com os objetivos e finalidades propostas, o que nesse caso significa comungar com a integração entre Ensino Médio e Ensino Técnico em um único curso, conforme nos permitiu o Decreto № 5.154/2004.

Dentre as diversas possibilidades de integração que podem ser criadas e adotadas, nos deteremos aqui a duas especificamente e que vêm sendo discutidas constantemente. A primeira trata da construção de um currículo integrado e a segunda da aplicação de práticas pedagógicas integradoras.

Em relação ao currículo integrado, é salutar considerarmos as dimensões da vida do educando com todas as pluralidades existentes, uma vez que os processos históricos, sociais, econômicos e culturais vivenciados por esses sujeitos precisam ser considerados e ressignificados a partir de fatos presentes. Sobre essa concepção de currículo integrado à vida do educando temos

Elementos significativos do passado, que precisam integrar-se aos fatos cruciais do presente. Elementos do conhecimento empírico e da cultura que trazem os educandos de suas experiências de vida que precisam juntar-se aos conhecimentos científicos para significá-los. (MACHADO, 2010, p.82).

Ainda sobre integração do currículo à vida do educando devemos considerar que nessa integração, os conteúdos gerais e técnicos possuem a mesma importância nesse processo de formação, e isso constitui outra barreira a ser superada já que tradicionalmente há uma separação entre esses conteúdos de acordo com o suposto grau de importância. Sendo assim, constata-se a necessidade de uma mudança de postura pedagógica tanto de professores quanto de alunos, o que Machado (2010, p. 82) coloca como sendo " uma ruptura com um modelo cultural que hierarquiza os conhecimentos e confere menor valor e até conotação negativa àqueles de ordem técnica". Para Machado (2010) essa integração curricular significa também como oportunidades para os profissionais do Ensino Médio e do Ensino Técnico, superarem as fragilidades de cada tipo de ensino (médio e técnico), enfrentarem a tensão dialética entre pensamento científico e pensamento técnico e buscarem outras relações entre teoria e prática. Portanto a integração curricular significa uma inovação na prática educativa, uma vez que essa não é estática e precisa ser alimentada de novos conhecimentos e ações.

Como mencionamos anteriormente, a segunda possibilidade de integração se refere ao uso de práticas pedagógicas que também possibilitem a integração entre o Ensino Médio e o Ensino Técnico. Vale esclarecer a princípio que toda prática pode ser integradora a partir do momento 
que foi pensada de acordo com os objetivos e finalidades propostos. Assim, uma prática considerada tradicional poderá ser ressignificada e considerada integradora à medida que seja aplicada de forma contextualizada e interdisciplinar, por exemplo.

Sobre contextualização Machado (2010, p. 87) diz que "constitui uma das condições de êxito no desenvolvimento das capacidades de compreender, relacionar, utilizar e praticar alguma mediação teórica ou técnica na implementação de qualquer atividade humana". Sendo assim, para que haja uma prática pedagógica contextualizada é preciso considerar os conhecimentos prévios dos educandos, reconhecê-los como sujeitos ativos no processo histórico e na sua trajetória de formação e possibilitar a relação entre as suas condições reais com o mundo de forma consciente para que seja possível a transformação desses educandos em sujeitos críticos capazes de provocar mudanças na realidade em que vive.

Portanto, é preciso que haja uma sistematização de ações integradas, no entanto, sem privilegiar qualquer disciplina ou conteúdo específico, uma vez que o primordial ou essencial é despertar as potencialidades do educando para que ele assuma um papel de agente transformador, o que vai demandar que se considere desde os interesses e necessidades dos alunos até o desenvolvimento do pensar, sentir e agir, condições essenciais para que aconteçam as aprendizagens significativas. Para tanto, os atores dos processos educativos e pedagógicos devem pensar e descobrir meios de possibilitar o ensino e a aprendizagem de forma integrada e que atenda ao ideário de sujeito detentor de uma formação humana e integral. Sobre essas possibilidades temos:

[...] faz-se necessário selecionar e organizar conteúdos que viabilizem o conhecimento da realidade vivida e das experiências desses sujeitos, que reafirmem seu potencial de protagonistas da história e da cultura. O processo educativo da modalidade do ensino integrado pode, para tanto, recorrer a propostas de ação didática que dialoguem e contribuam para o desenvolvimento de formas organizativas de alunos e professores que sejam instâncias mediante as quais possam contribuir para intervir na realidade social em que vivem. (MACHADO, 2010, p. 89).

Ainda sobre a efetivação de práticas integradoras, o princípio da interdisciplinaridade deve ser pensado e incluído a partir do momento de planejamento dessas práticas. Podemos definir a interdisciplinaridade de forma mais simples como sendo a interação entre duas ou mais disciplinas, no entanto os conceitos são diversos apesar de todos indicarem uma harmonização dos diversos saberes e conhecimentos construídos. Machado (2010) sugere a metodologia de ensino orientada por projetos como sendo uma possibilidade de vincular teoria e prática, aproximar o processo de ensino-aprendizagem da realidade e instigar a curiosidade do aluno a fim de que ele se torne sujeito do processo de produção de conhecimento, entre outras potencialidades que o trabalho com projetos propicia.

Assim, a integração curricular e o uso de práticas integradoras constituem possibilidades para a efetivação do Ensino Médio integrado e consequentemente de uma formação humana integral, desde que estejam sendo planejadas a partir de objetivos e finalidades condizentes com a realidade existente e a partir de um projeto de sociedade que vise à transformação social. Segundo Pistrak (2000), só pode haver prática pedagógica revolucionária a partir de uma teoria pedagógica revolucionária. 


\section{CONSIDERAÇÕES FINAIS}

No decorrer do texto buscou-se enfatizar a relevância do Ensino Médio Integrado na formação humana integral dos sujeitos, considerando as finalidades dessa última etapa da Educação Básica. Além disso, buscou-se enfatizar também a importância das práticas pedagógicas integradoras na efetivação desse Ensino Médio Integrado que se apresenta como uma das possibilidades de projeto educacional voltado para a realidade e provedor de subsídios indispensáveis na formação do sujeito crítico e consciente.

No entanto, ficou explícito que a integração é possível, mas não podemos listar um conjunto de práticas pedagógicas integradoras, uma vez que o problema requer soluções mais amplas e que partam das dimensões ética e política da realidade, para então planejar as soluções didático-pedagógicas. Segundo Araújo e Rodrigues (2012), definir as finalidades políticas e educacionais emancipadoras e assumir o compromisso com essas finalidades é a condição para que o projeto de Ensino Médio Integrado seja de fato concretizado.

Somente com a definição dos objetivos e finalidades educacionais emancipatórias e assumindo o compromisso de efetivação de ações que possibilitem a efetivação desses objetivos e finalidades é que podemos de fato construir um currículo com a devida articulação dos conhecimentos e desenvolver práticas contextualizadas que contemplem todas as dimensões de conhecimentos necessárias na Educação Básica.

Dessa forma, só nos resta fazer o convite aos educadores em geral para se debruçarem na construção desse projeto de integração a partir da leitura e interpretação crítica da realidade e da compreensão da relação existente entre as dimensões históricas, políticas, sociais, econômicas e culturais ao determinar a vida dos sujeitos na sociedade. Portanto a integração constitui uma possibilidade e um grande desafio para se alcançar a formação humana integral.

\section{REFERÊNCIAS}

1. BRASIL. Congresso Nacional. Lei Federal $n \cong$ 9.394. Lei de Diretrizes e Bases da Educação Nacional. 20 de dezembro de 1996.

2. CANDAU, V. M. Rumo a uma nova didática. 6a ed. Petrópolis,RJ: Vozes, 1994.

3. FRIGOTTO, Gaudêncio; CIAVATTA, Maria; RAMOS, Marise. A gênese do Decreto n. 5.154/2004: um debate no contexto controverso da democracia restrita. In: (Org.) Ensino Médio Integrado: concepção e contradições. São Paulo: Cortez, 2005.

4. FRIGOTTO, Gaudêncio. Ensino Médio e Técnico profissional: disputa de concepções e precariedade. São Paulo, Jornal Le Monde Diplomatique Brasil. Ano 6, no 68, março de 2013, p.28-29.

5. FRIGOTTO, Gaudêncio; CIAVATTA, Maria. Perspectivas sociais e políticas da formação de nível médio: avanços e entraves nas suas modalidades. Educ. Soc., Campinas, v. 32, n. 116, set. 2011.

6. HENGEMÜHLE, ADELAR. Gestão de ensino e práticas pedagógicas. Petrópolis: Vozes, 2004.

7. KUENZER, Acácia. Da dualidade assumida à dualidade negada: o discurso da flexibilização justifica a inclusão excludente. In: Educ. Soc., Campinas, vol. 28, n. 100 - Especial, p. 1153- 
1178, out. 2007. Disponível em: <http://www.cedes.unicamp.br>

8. KUENZER, Acácia. O Ensino Médio no plano nacional de educação 2011-2020: superando a década perdida? In: Educ. Soc., Campinas, v. 31, n. 112, jul-set. 2010.

9. MARX, Karl. O capital. Coleção Os economistas. São Paulo: Círculo do Livro Ltda,1996.

10. MARX, Karl; ENGELS, Friedrich. O manifesto do Partido Comunista. São Paulo. Editora Boitempo, 1ㄹed. 1998.

11. MACHADO, Lucília Regina de Souza. Ensino Médio e técnico com currículos integrados: propostas de ação didática para uma relação não fantasiosa. In: JAQUELINE MOLL \& Colaboradores. (Org.). Educação Profissional e tecnológica no Brasil contemporâneo: Desafios, tensões e possibilidades. Porto Alegre, RS: ARTMED, 2009, p.80-95.

12. MOURA, Dante. Ensino Médio e educação profissional nos anos 2000: movimentos contraditórios. In: (Org.) Produção de conhecimento, políticas públicas e formação docente em educação profissional. Campinas/SP: Mercado das letras, 2013.

13. PISTRAK. Fundamentos da Escola do Trabalho. São Paulo: Expressão Popular, 2000.

14. RAMOS, Marise. Possibilidades e desafios na organização do currículo integrado. In: FRIGOTTO, Gaudêncio; CIAVATTA, Maria; RAMOS, Marise. Ensino Médio Integrado: concepções e contradições. São Paul: Cortez, 2005.

15. SAVIANI, Dermeval. O choque teórico da politecnia. Educação, Trabalho e Saúde, Rio de Janeiro: EPSJV/FIOCRUZ, v. 1, p. 131-152, 2003. 